\title{
On the formation of hörnesite in a Fatimid manuscript folio
}

\author{
Yana van Dyke ${ }^{1}$, Silvia A. Centeno $2^{*} \mathbb{D}$, Federico Carò ${ }^{2}$, James H. Frantz² and MarkT. Wypyski²
}

\begin{abstract}
A folio fragment attributed to the Fatimid period in Egypt was found to bear tufts of white crystals associated with the orange-brown and yellow paints. Raman spectroscopy identified a mixture of arsenic sulfide-based pigments in the orange-brown and yellow areas, along with vermilion in the outlines of the figures. $X$-ray microdiffraction, Raman spectroscopy, and energy-dispersive $X$-ray spectrometry identified the white crystals as hörnesite $\left[\mathrm{Mg}_{3}\left(\mathrm{AsO}_{4}\right)_{2} \cdot 8 \mathrm{H}_{2} \mathrm{O}\right]$. Synthesis of this compound at ambient temperature and elevated relative humidity over a period of 3 years, on paper painted with arsenic sulfide pigments and treated with magnesium carbonate, suggests the possibility that a magnesium-based deacidification treatment may have contributed to the formation of this phase on the folio fragment. This work highlights the potential damage that may be sustained by arsenic sulfide-based media through exposure to deacidifying suspensions such as the ones often used in the past to treat works of art on paper and historic documents.
\end{abstract}

Keywords: Hörnesite, Realgar, Pararealgar, Fatimid manuscript, Deacidification

\section{Introduction}

The chemistry of the arsenic sulfides and, in particular, the photodegradation of realgar $\left(\alpha-\mathrm{As}_{4} \mathrm{~S}_{4}\right)$ as found in works of art and mineral collections have been extensively studied [1-8]. These studies have indicated the transformation of realgar to proceed stepwise through the intermediate $x$-phase to the yellow polymorph of realgar, pararealgar $\left(\mathrm{As}_{4} \mathrm{~S}_{4}\right)$ and, ultimately, to arsenolite $\left(\mathrm{As}_{2} \mathrm{O}_{3}\right)$. In the effort to explain the mechanism for this transformation, it has been proposed that incident light breaks As-As bonds in realgar, in preference to the stronger As-S bonds, thereby liberating free arsenic that is then intercalated in the rearranged cages of the pararealgar structure [7]. What has been shown to be the specific photosensitivity of realgar to wavelengths of visible light between 500 and $670 \mathrm{~nm}$ presents an intractable issue by itself where the display of works of art or mineral specimens is a concern. The physical alteration associated with the chemical degradation of arsenic-containing

\footnotetext{
${ }^{*}$ Correspondence: silvia.centeno@metmuseum.org

${ }^{2}$ Department of Scientific Research, The Metropolitan Museum of Art,

1000 Fifth Avenue, New York, NY 10028, USA

Full list of author information is available at the end of the article
}

pigments, often seen as cracking and crumbling of paint layers and surfaces, poses a major conservation challenge $[1,9,10]$.

However, beyond the structural breakdown of realgar and the consequent change in color, further effects are implied as a result of the dissolution of arsenolite in aqueous media, its oxidation to arsenic pentoxide and reaction with cations to form insoluble arsenates $[1,11]$. As a possible example of one of these effects, we report here an occurrence of the magnesium arsenate mineral, hörnesite $\left[\mathrm{Mg}_{3}\left(\mathrm{AsO}_{4}\right)_{2} \cdot 8 \mathrm{H}_{2} \mathrm{O}\right]$, that illustrates yet another potential alteration product of arsenic sulfide pigments.

This occurrence was discovered on a rare, doublesided folio attributed to the Fatimid period in Egypt (969-1171 CE) and that is now held in the Department of Islamic Art at The Metropolitan Museum of Art (MMA acc. no. 54.108.3; Fig. 1a, b). Considered to be one of the earliest works in the Islamic collection, the folio was purchased by the museum in 1954 together with three other paintings on paper, all of which were reportedly found at the excavation site of Fustat in Old Cairo [12]. These works belong to a small group of surviving folios and their fragments that may once have been pages in bound 


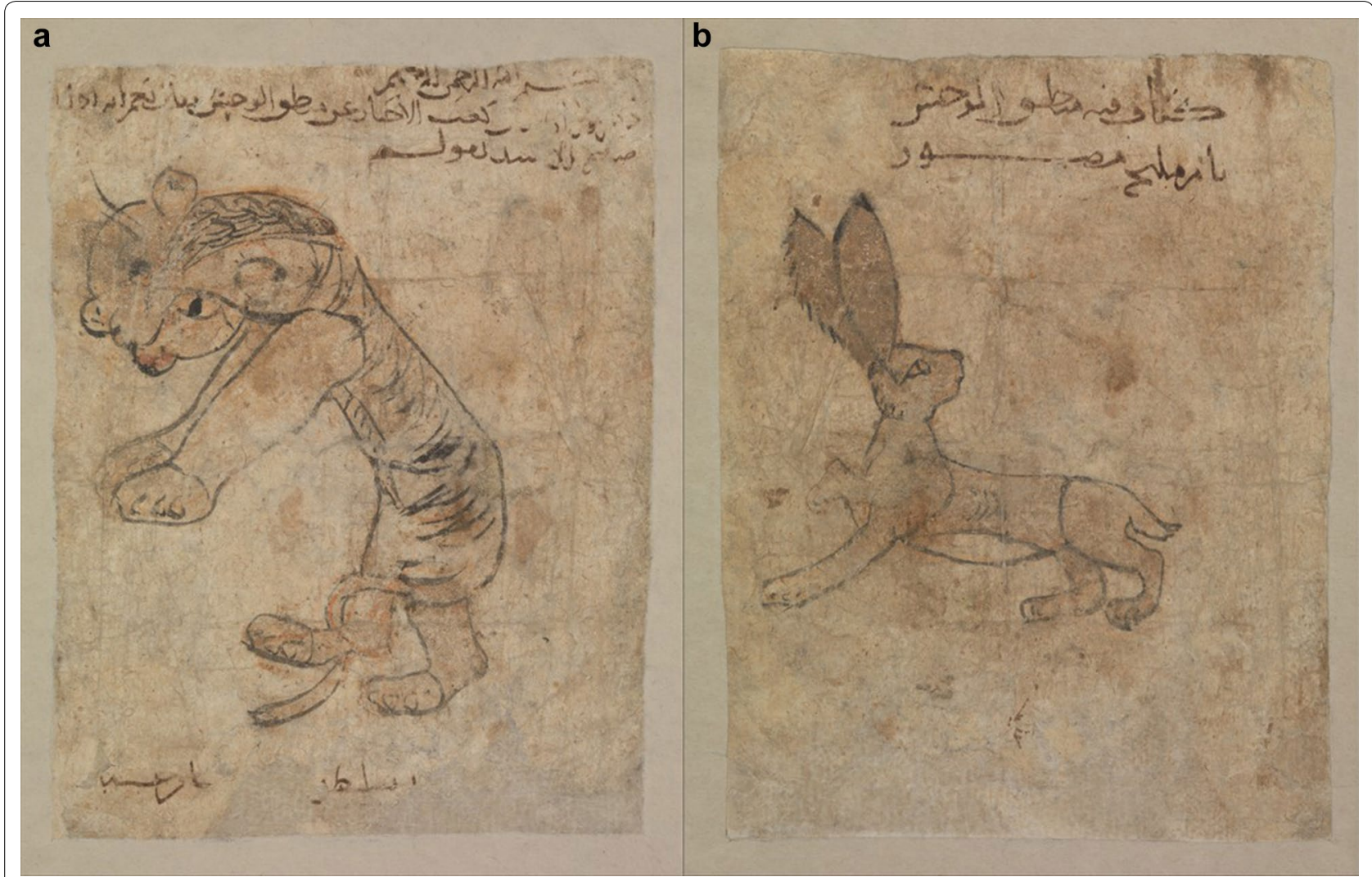

Fig. 1 a Recto of Fatimid folio depicting a lion. b Verso of same showing a hare. The Metropolitan Museum of Art, New York, Purchase, Rogers Fund, 1954 (54.108.3)

manuscripts, of which no intact examples are believed to remain $[12,13]$.

On the page considered here, one side, labeled as the recto on the Museum's website [14], depicts a lion in broad, brush-worked passages of what appears to be a muted and darkened yellow and orange paint, with outlines, details and verses of text rendered in black ink (Fig. 1a). The other side, labeled as the verso, depicts a hare with elongated ears and turned head, poised as if ready to jump. The features on this side appear to have been executed by the same hand, in the same style, and with the same palette as those on the side depicting the lion (Fig. 1b). Interpretations of the authorship and original context of the folio vary according to how the fragmentary Arabic inscriptions and literary associations are to be understood. One opinion emphasizes the text on the side bearing the lion, with a translation that reads, "In the name of God, the Merciful, the Compassionate/ Ka'b al-Ahbar narrated and... through the speech of wild animals.../...the lion for the purpose of his teaching", suggesting an association with a didactic tradition of fable literature [15]. Other views point to the text on the side with the hare and its partial translation as "Book on the speech of wild animals", suggesting it to belong to Arab literary practices related to the classical Greek tradition of scientific handbooks and zoological treatises [12]; still other researchers have doubted whether the folio belonged to a book at all, citing the possibility that the inscriptions may well have been added at a later date [16]. Whatever its original context, the folio appears to be derived from or otherwise related to a manuscript titled, The Speech of Wild Animals, by the early author Ka'b al-Ahbar (d. 652/3) that was copied and expanded by Muslim scholars for centuries [17, 18]. As such, the folio belongs to the traditions established by Fatimid rulers, whose patronage of decorative arts and scientific inquiry led to novel figural forms that relied heavily on naturalistic animal motifs, featuring winged birds, spritely hares, and powerful lions [19]. Leaving aside the interesting issue of original purpose, our concern here is the present condition of the folio and, specifically, the discovery of an apparent alteration product affecting the orange and yellow pigments on both its surfaces.

The folio fragment was examined and analyzed by noninvasive techniques first to identify the pigments and the white crystals. The need to firmly identify these crystals 
and further characterize them prompted the removal of microsamples. To test whether paper deacidification treatments with $\mathrm{Mg}$-based reagents may be responsible for the formation of the white crystals observed, experiments were carried out on paper samples painted with a mixture of As-based pigments in an aqueous gum arabic medium, followed by treatment with a $\mathrm{MgCO}_{3}$ suspension.

\section{Experimental}

A preliminary examination of both sides of the folio under low-power magnification revealed tufts of white acicular crystals superimposed on and exclusively associated with striated laths of orange and yellow pigment particles suggestive of arsenic sulfides (Fig. 2). To characterize the furnish of the paper, a microscopic fiber sample was removed from an edge of the folio and examined by polarized light microscopy (PLM), first as wetted with water and subsequently with Graff " $C$ " stain, at $100 \times$, $200 \times$, and $400 \times$ magnifications.

Raman spectra of the orange and yellow pigments were acquired in situ, while samples of the white crystals were removed for analysis. A Renishaw System 1000 coupled to a Leica DM LM microscope was employed. A $785 \mathrm{~nm}$ laser excitation was chosen to avoid degradation of arsenic sulfide pigments that is known to occur when these pigments are exposed to light between 500 and $670 \mathrm{~nm}$ [7]. A 1200 lines $/ \mathrm{mm}$ grating and a thermoelectrically cooled CCD detector were used. The laser beam was focused on the sample areas using a $50 \times$ objective lens with the power at the sample surface set to $0.2-1 \mathrm{~mW}$

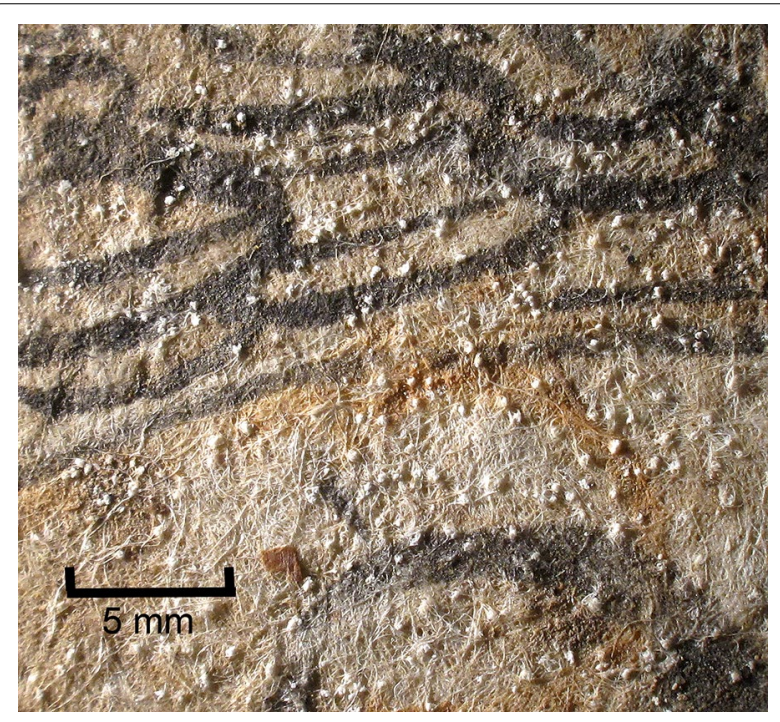

Fig. 2 Photomicrograph of white crystals associated with arsenic-containing pigments found on the Fatimid folio as viewed with a binocular microscope using neutral density filters. Spectra were recorded with integration times between 60 and $240 \mathrm{~s}$.

Using a tungsten needle under high magnification, samples of the white crystals found on the folio were also removed for analysis by energy-dispersive X-ray spectrometry (EDS), Raman spectroscopy and X-ray microdiffraction (XRD). No usable sample of the orange pigment could be removed for XRD analysis without risking damage to the surface of the folio. For this reason, only a few particles were sampled, and analyzed by SEM-EDS.

Scanning electron microscopy-energy dispersive X-ray spectrometry analyses (SEM-EDS) were performed with a Zeiss Sigma field emission-scanning electron microscope, equipped with an Oxford Instruments X-MaxN 80 SDD detector. Backscattered electron (BSE) images were acquired and EDS analyses were performed on uncoated samples mounted on carbon stubs under low vacuum (ca. $60 \mathrm{~Pa}$ ) with an accelerating voltage of $20 \mathrm{kV}$. X-ray microdiffraction analyses were performed using a Rigaku Dmax/Rapid instrument. The analyses were conducted with $\mathrm{Cu} \mathrm{K \alpha}$ radiation, an $800 \mu \mathrm{m}$ collimator, and a graphite monochromator on the incident beam. Specimens were mounted on glass fibers with Ambroid ${ }^{\circledR}$ nitrocellulose binder and oscillated about two axes of the goniometer during 15-min exposures. Patterns were interpreted with Jade 9.0 software from Materials Data, Inc. and the ICDD PDF-4+ database.

Strips of Whatman ${ }^{\circledR}$ filter paper were painted with a ground mineral specimen containing a mixture of orpiment, realgar, and pararealgar (Ward's Scientific) dispersed in an aqueous gum arabic medium. Subsequently, a $\mathrm{MgCO}_{3}$ suspension was applied drop wise to the painted surfaces. The paper strips were then placed in sealed vials with sufficient water to insure a high relative humidity and allowed to age at room temperature with exposure to ambient laboratory lighting. These paper strips were examined monthly using a binocular microscope.

The mixture of yellow-orange arsenic-based pigments used to prepare the laboratory samples was determined by XRD to be predominantly a mixture of orpiment $\left(\mathrm{As}_{2} \mathrm{~S}_{3}\right)$ with realgar $\left(\alpha-\mathrm{As}_{4} \mathrm{~S}_{4}\right)$ and pararealgar $\left(\mathrm{As}_{4} \mathrm{~S}_{4}\right)$. The magnesium carbonate suspension used was prepared by adding $5 \mathrm{~g}$ of $\mathrm{MgCO}_{3}$ (Fisher Scientific) to $100 \mathrm{~mL}$ of distilled water and allowed to stand overnight.

\section{Results and discussion}

The paper support and the orange-yellow pigments

The microscopic examination of the paper sample by PLM revealed the furnish to consist of $80 \%$ bast and $20 \%$ cotton fibers, with protein and carbohydrate constituents. The absence of associated cellular material in 


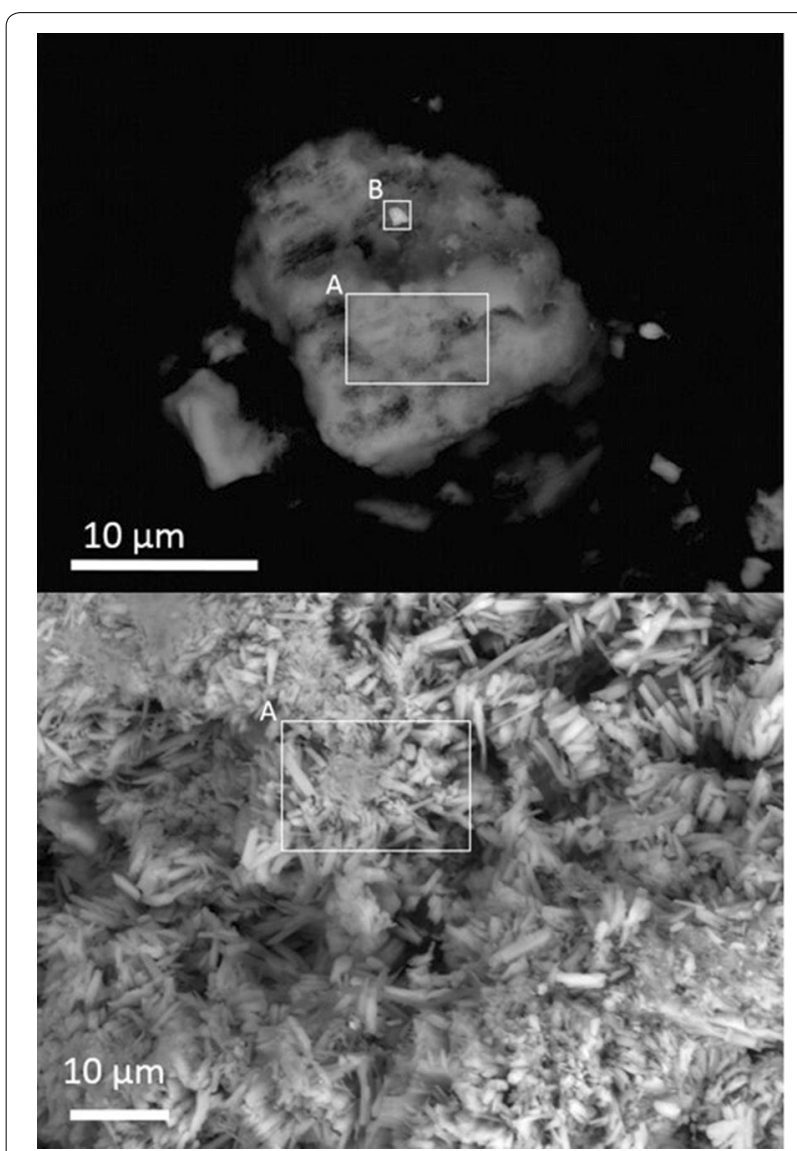

Fig. 3 Backscattered electron images of samples of the orange-yellow pigment (top, $\times 2850$ ), and of the white crystals (bottom, $\times 1500$ ) obtained from the recto of the folio. The letters refer to the locations where the spectra shown in Fig. S1 (Additional file 1) and Fig. 5 were acquired the sample also suggested that the paper was not made directly from plant material, but rather from secondary or tertiary forms of recycled cloth or other material. A photomicrograph of the stained fibers is included in Additional file 1: Figure S2.

EDS analysis of the orange-yellow crystals removed from the folio (Fig. 3, top) identified As and S as major elements in an approximate atomic ratio of 1:1. A few small particles that appear brighter in the BSE image (Fig. 3, top) were found to contain $\mathrm{Hg}$ and S. The corresponding EDS spectra are included in the Additional file 1: Figure S1A, B. Raman spectra acquired in situ from the orange-yellow and yellow pigment particles used to paint the bodies of the lion and hare gave bands at ca. 172, 187, 191, 201, 220, 234, 273, 318, 331, 344 , and $361 \mathrm{~cm}^{-1}$ that are consistent with frequencies reported for mixtures of pararealgar and the orange $x$-phase (Fig. 4) [5]. The shoulders at ca. $183 \mathrm{~cm}^{-1}$ and at $211 \mathrm{~cm}^{-1}$ in this spectrum may indicate the presence of realgar [5]. Other bands reported for realgar overlap those of pararealgar and/or the $\mathrm{X}$-phase, while additional bands observed at ca. 137 and $149 \mathrm{~cm}^{-1}$ cannot be firmly assigned. Strong and medium-strong Raman bands expected for orpiment at ca. 292 and $309 \mathrm{~cm}^{-1}$ are not observed in the spectra acquired in the orange-yellow and yellow paint areas. A strong feature is expected at ca. $353 \mathrm{~cm}^{-1}$ for orpiment, and a maximum at this frequency is visible in the spectrum shown in Fig. 4; however, the $X$-phase and realgar also give strong bands at this frequency. In the spectra recorded from the yellow areas, a relatively weak band was also observed at ca. $1087 \mathrm{~cm}^{-1}$, likely due to calcium carbonate [20]. This band is above the range of

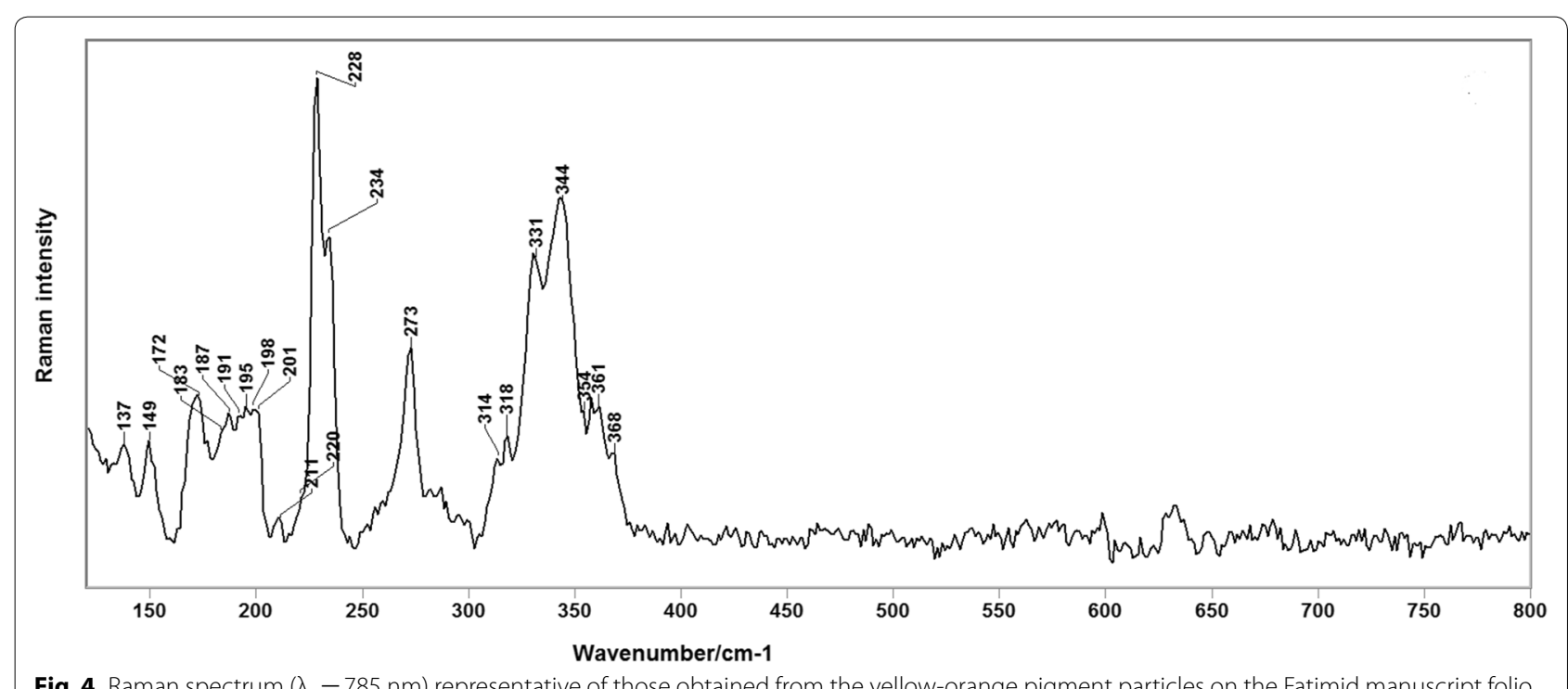

Fig. 4 Raman spectrum $\left(\lambda_{0}=785 \mathrm{~nm}\right)$ representative of those obtained from the yellow-orange pigment particles on the Fatimid manuscript folio 
the spectrum presented in Fig. 4. Arsenolite was not detected by Raman spectroscopy in the painted areas of the folio. Analysis of the red outlines seen on figures, such as those delineating the head and upper part of the lion's back (Fig. 1a), showed characteristic Raman bands for vermilion $(\alpha-\mathrm{HgS})$ at ca. 252, 282 and $343 \mathrm{~cm}^{-1}$. These results suggest that the figures in the Fatimid folio were originally painted red-orange with realgar and possibly other arsenic sulfides, and that their present, less intense hue is due to photodegradation.

\section{The white crystalline overgrowth}

EDS analysis of samples of the white crystals removed from the folio (Fig. 3, bottom) found As and Mg as principal elemental components (Fig. 5a). Raman spectra acquired from these crystals showed main bands at ca. 810 and $880 \mathrm{~cm}^{-1}$ that are consistent with data reported for the $\mathrm{AsO}_{4}{ }^{3-}$ ion (Fig. 5b) [21]; the feature expected at ca. $365 \mathrm{~cm}^{-1}$ for this ion is within the signal to noise ratio in the spectra obtained. X-ray microdiffraction analysis of the white crystals yielded a well-defined pattern with numerous sharp lines. An unrestricted search
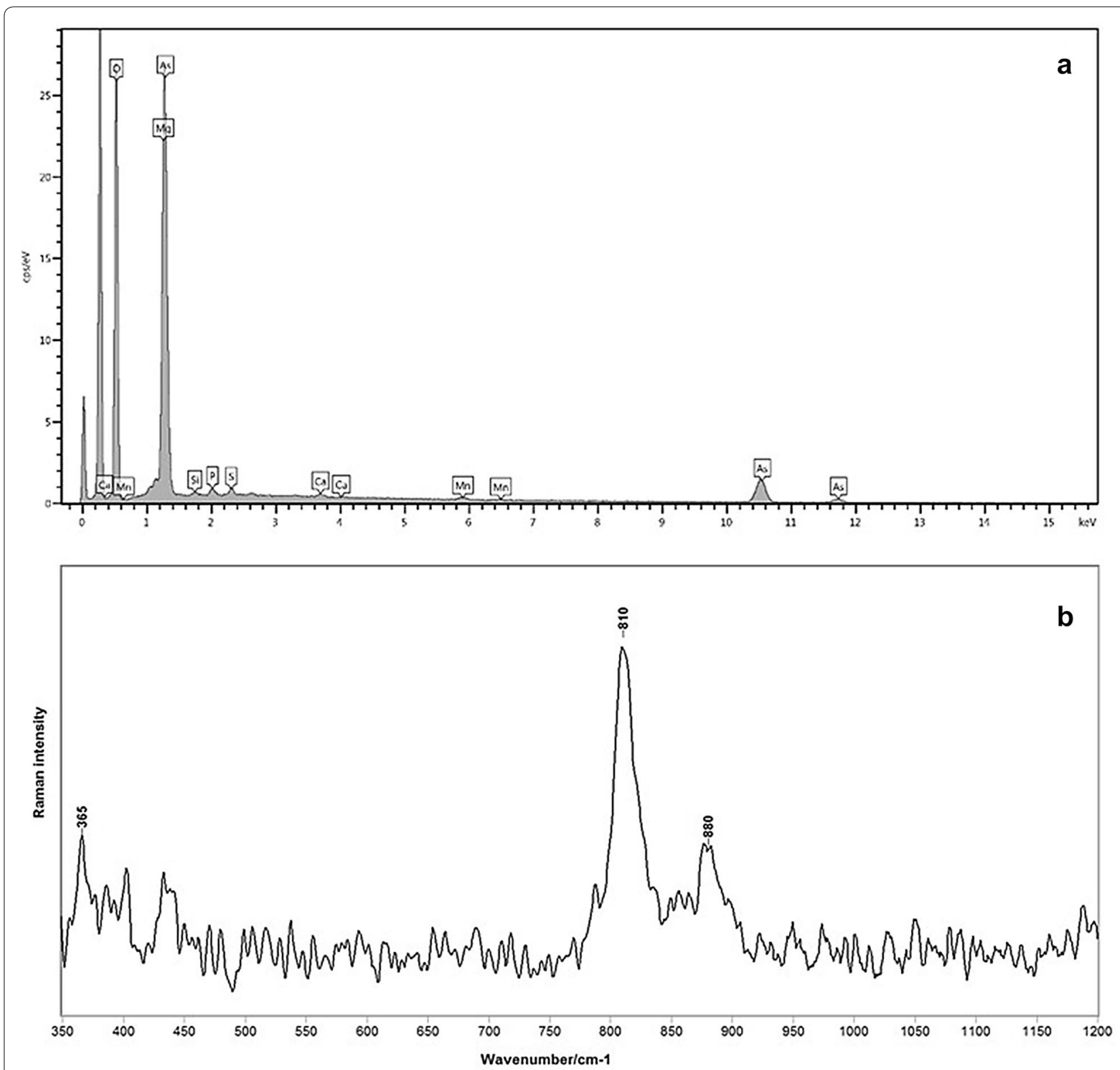

Fig. 5 a EDS spectrum acquired in the area labeled as A in the bottom image of Fig. 3. $\mathbf{b}$ Raman spectrum $\left(\lambda_{0}=785 \mathrm{~nm}\right)$ acquired from the white crystals on the Fatimid manuscript folio 
of the entire ICDD PDF-4+ database matched the pattern of hörnesite $\left[\mathrm{Mg}_{3}\left(\mathrm{AsO}_{4}\right)_{2} \cdot 8 \mathrm{H}_{2} \mathrm{O}\right]$ with a very high level of confidence. The file pattern for this mineral effectively accounts for the entire pattern of the unknown with excellent matches for all d-values and intensities. No other phases, including arsenolite, were detected (Fig. 6). A table listing the XRD data is included in the Additional file 1: Table S1. The XRD results are consistent with the EDS and Raman results discussed above as well as with the observed texture and morphology of the material, which compare favorably with published images of the mineral as found in nature [22].

Hörnesite belongs to the so-called vivianite group that includes several other arsenate and phosphate members with the structural formula, $\mathrm{M}_{3}\left(\mathrm{XO}_{4}\right)_{2} \cdot 8 \mathrm{H}_{2} \mathrm{O}$, where $\mathrm{M}$ represents a divalent cation and $\mathrm{X}$ is either $\mathrm{As}$ or $\mathrm{P}$. In other contexts, hörnesite is reported as a common Asbearing species in arsenic-contaminated soils, where it is thought to be formed by the reaction of As with mobile Mg ions [23-25]. The mineral has also been found in underground cave settings in association with other arsenates [26], and mineral specimen images have been published showing hörnesite as an overgrowth on arsenic sulfides [27].

It has been proposed that when orpiment and realgar photodegrade, arsenic trioxide is formed, which, if water is present, may dissolve and further oxidize to arsenic pentoxide; the latter species may then react with ions present such as lead, calcium and others, and become deposited in the paint system as an arsenate [1,11]. Whether such is the mechanism in the present case remains a topic for further study. However, the results recall the widespread use of Mg-based reagents for the deacidification of paper documents and works of art and prompt the question as to the origin of this occurrence. These treatments have been developed to address the acid hydrolysis of cellulose, the major component of paper, that can lead to severe degradation of its mechanical properties [28]. Sources of acid in papers include organic acids that may form from the decomposition of residual lignin during the natural ageing of the paper [29, 30], as well as environmental pollutants, such as sulfur dioxide, nitrous oxide and nitrogen dioxide. Housing and mounting materials and artistic media, such as inks, paints, and adhesives, also present a risk [31-33]. Various deacidification methods have been proposed to remove or reduce the acidity of paper (see, for example, [29, 31, 34-36]). Treatments that involve immersion of the paper in aqueous alkaline solutions were introduced at the end of the nineteenth century, and basically consist in the use of reagents such as calcium hydroxide, calcium bicarbonate and magnesium bicarbonate to neutralize the acidity and

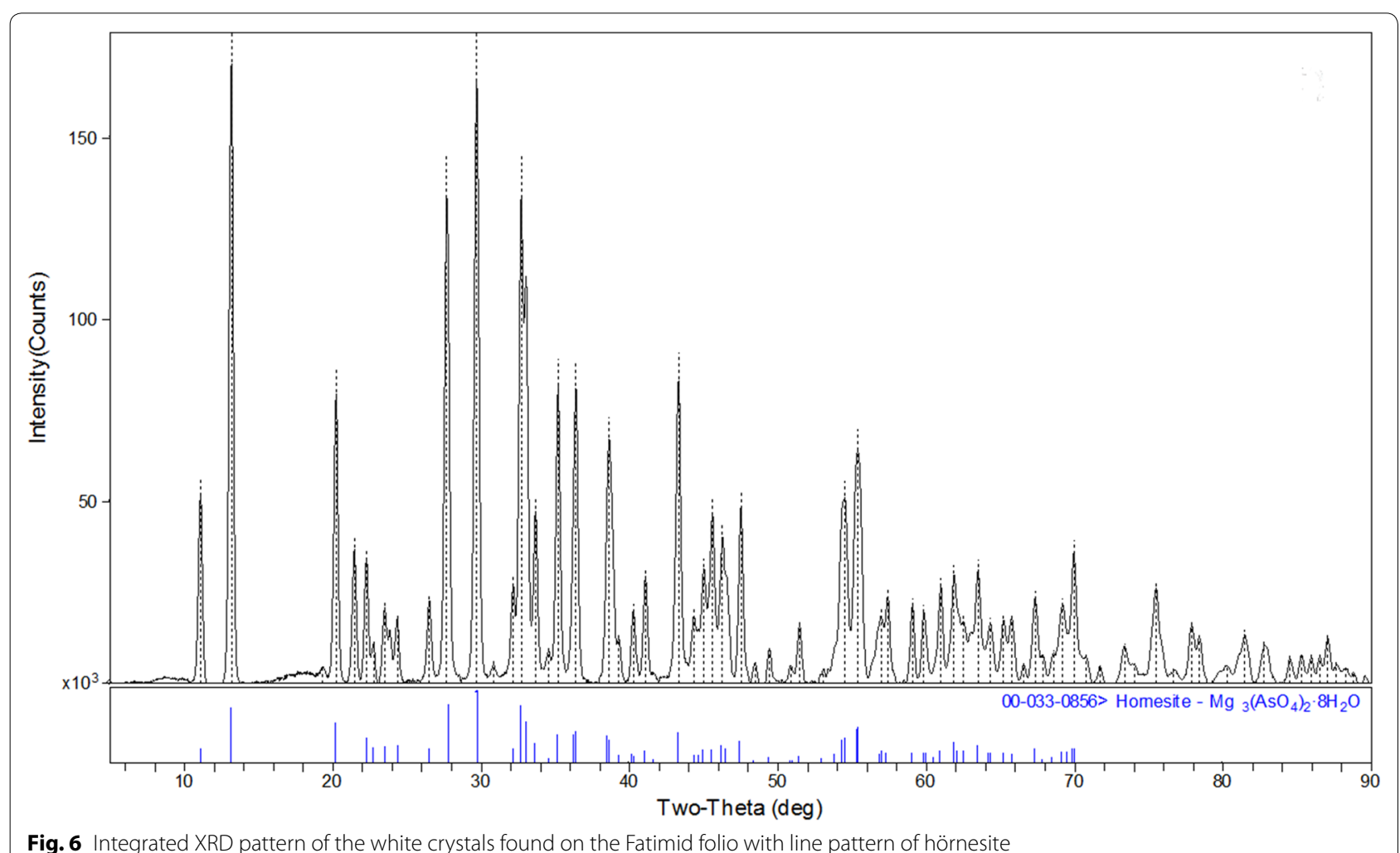



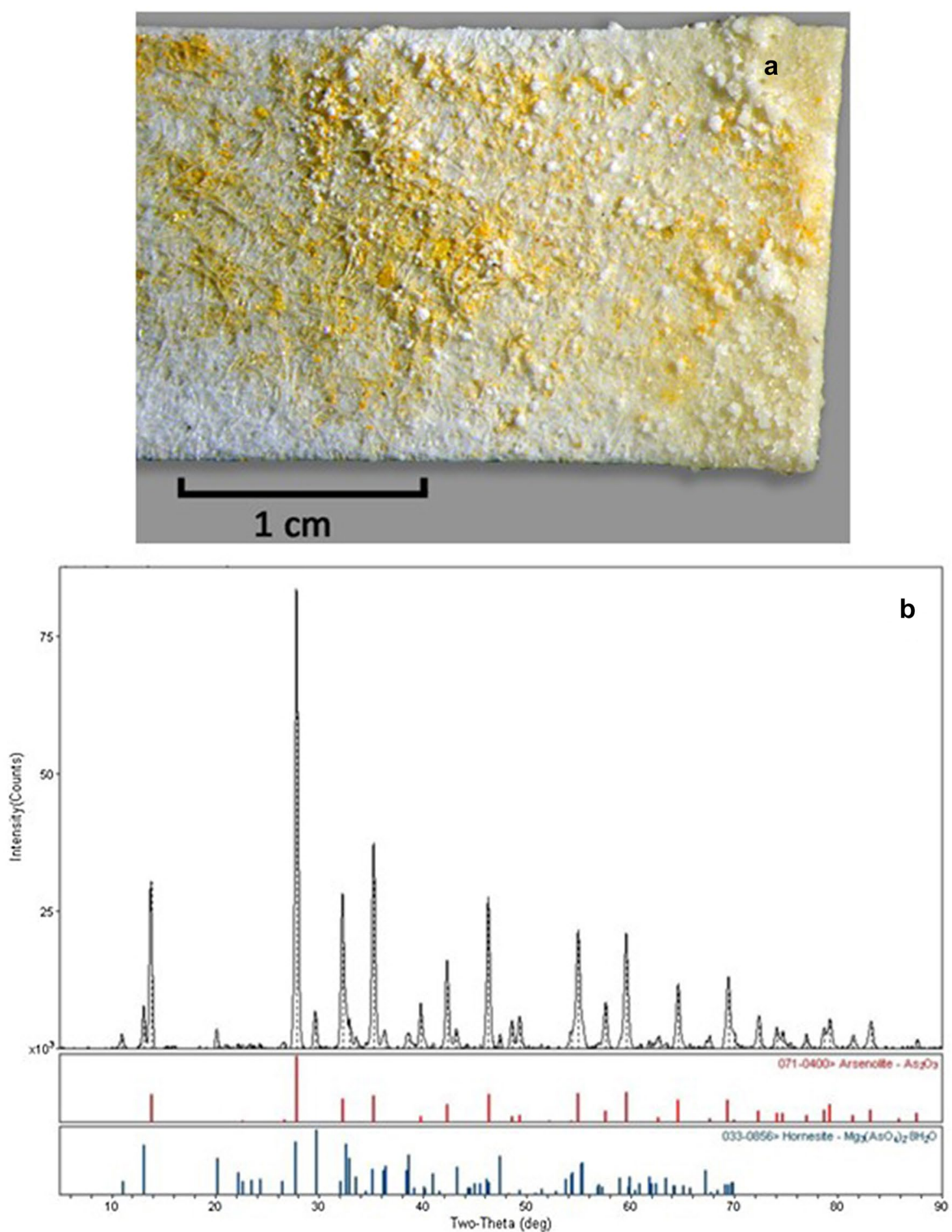

Fig. 7 a Photomicrograph of white crystals grown after 3 years on a mixture of orpiment, realgar and pararealgar applied on Whatman ${ }^{\circledR}$ filter paper and treated with $\mathrm{MgCO}_{3}$ suspension. Visible illumination, original magnification $\times 10$. $\mathbf{b}$ Integrated XRD pattern of the white crystals formed on the sample shown in $\mathbf{a}$, with line patterns of arsenolite and hörnesite 
reportedly provide an alkaline reserve that may protect the paper against further acidic attack [29, 31, 36-38]. While it has been reported that the calcium-containing compounds give better results compared to magnesiumcontaining ones due to an increased bond strength of the cellulose, both types of reagents have been widely used $[33,36,39]$.

\section{Synthesis of the white crystals}

To explore the possibility that paper deacidification treatments with Mg-based reagents might lead to reaction with arsenic sulfide pigments to produce hörnesite, strips of filter paper painted with a mixture of orpiment, realgar, and pararealgar, in an aqueous gum arabic medium, were treated with a $\mathrm{MgCO}_{3}$ suspension and allowed to age at a high relative humidity and room temperature as described in the Experimental section. After 3 years, tufts of a white material were observed to have formed on their painted surfaces (Fig. 7a). X-ray microdiffraction analysis of the white material yielded a well-defined pattern with more than forty sharp lines in the frontreflection region. An unrestricted search of the ICDD PDF-4+ database resolved the pattern with a high level of confidence as representing predominantly arsenolite with strong evidence of hörnesite (Fig. 7b). A table listing the XRD data is included in Additional file 1: Table S2. These results suggest both the relative ease with which the arsenate may be formed as well as the conditions of time and/or environment necessary for the transformation to hörnesite, which appear to have been achieved completely on the folio but only partially on our synthetic example.

\section{Conclusions}

The white crystalline material found associated with, and seemingly derived from, the yellow-orange arsenic sulfide pigments on the Fatimid folio fragment was determined to be the magnesium arsenate hörnesite, $\left[\mathrm{Mg}_{3}\left(\mathrm{AsO}_{4}\right)_{2} \cdot 8 \mathrm{H}_{2} \mathrm{O}\right]$. While we have no record of treatment or other direct evidence to support an assignment of cause for this occurrence, the common usage of $\mathrm{Mg}$ based reagents for the deacidification of art and archival works on paper-especially in archaeological fieldworksuggests the possibility that in this instance the hörnesite may be a reaction product of such treatment. This conjecture may be supported by the apparent ease with which we have been able to synthesize hörnesite by aging, at high relative humidity and ambient temperature, a mixture of orpiment, realgar, and pararealgar applied on filter paper and treated with a $\mathrm{MgCO}_{3}$ suspension, as well as by the well-documented sequestering of As by mobile $\mathrm{Mg}$ ions in As-bearing soils to form the arsenate. This work highlights the potential damage that can be sustained by works bearing arsenic sulfide-based pigments through exposure to aqueous deacidifying suspensions often used to treat works of art on paper and historic documents in museums and other institutions. Ultimately, in the case of the Fatimid folio, no conservation intervention was undertaken. The hörnesite presently exists on a scale that does not interfere with the aesthetic reading of the work of art, nor does it appear to present cause for concern with respect to long-term physical or chemical stability.

\section{Additional file}

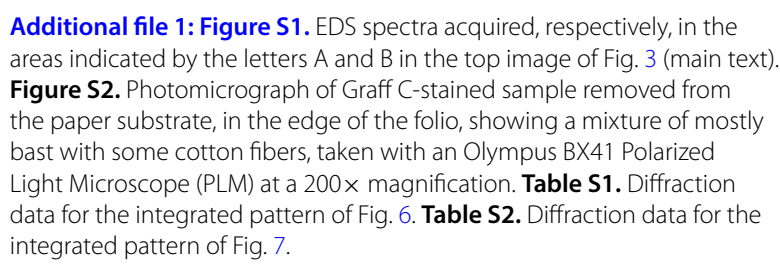

Additional file 1: Figure S1. EDS spectra acquired, respectively, in the areas indicated by the letters $A$ and $B$ in the top image of Fig. 3 (main text). Figure S2. Photomicrograph of Graff C-stained sample removed from the paper substrate, in the edge of the folio, showing a mixture of mostly bast with some cotton fibers, taken with an Olympus BX41 Polarized Light Microscope (PLM) at a 200× magnification. Table S1. Diffraction data for the integrated pattern of Fig. 6. Table S2. Diffraction data for the integrated pattern of Fig. 7.

\section{Authors' contributions}

YvD contributed the initial background and discovery of the white crystalline overgrowth. JHF, SC, FC, and MW performed the analytical work and interpretation of data. All authors were involved in drafting the manuscript. All authors read and approved the final manuscript.

\section{Author details}

${ }^{1}$ Department of Paper Conservation, The Metropolitan Museum of Art, 1000 Fifth Avenue, New York, NY 10028, USA. ${ }^{2}$ Department of Scientific Research, The Metropolitan Museum of Art, 1000 Fifth Avenue, New York, NY 10028, USA.

\section{Competing interests}

The authors declare that they have no competing interests.

\section{Availability of data and materials}

All the data supporting the conclusions are included within the article. Additional SEM and PLM images and detailed EDS analyses are available upon request from the Department of Scientific Research at The Metropolitan Museum of Art.

\section{Ethics approval and consent to participate}

Not applicable.

\section{Funding}

All the research was funded by The Metropolitan Museum of Art.

\section{Publisher's Note}

Springer Nature remains neutral with regard to jurisdictional claims in published maps and institutional affiliations.

Received: 16 July 2018 Accepted: 6 September 2018

Published online: 14 September 2018

\section{References}

1. Keune K, Mass J, Mehta A, Church J, Meirer F. Analytical imaging studies of the migration of degraded orpiment, realgar, and emerald green pigments in historic paintings and related conservation issues. Heritage Sci. 2016;4(1):10. 
2. Bonazzi P, Bindi L. A crystallographic review of arsenic sulfides: effects of chemical variations and changes induced by exposure to light. Z Kristallogr. 2008;223:132-47.

3. Daniels $V$, Leach $B$. The occurrence and alteration of realgar on ancient Egyptian papyri. Stud Conserv. 2004;49(2):73-84

4. Ballirano P, Maras A. Preliminary results on the light-induced alteration of realgar: kinetics of the process. Plinius. 2002;28:35-6.

5. Trentelman K, Stodulski L, Pavlosky M. Characterization of pararealgar and other light-induced transformation products from realgar by Raman microspectroscopy. Anal Chem. 1996;68(10):1755-61. https://doi. org/10.1021/ac951097o.

6. Corbeil M-C, Helwig K. An occurrence of pararealgar as an original or altered artists' pigment. Stud Conserv. 1995;40:133-8.

7. Douglass D, Shing C. The light-induced alteration of realgar to pararealgar. Am Mineral. 1992;77:1266-74.

8. Kyono A, Kimata M, Hatta T. Light-induced degradation dynamics in realgar: in situ structural investigation using single-crystal X-ray diffraction study and X-ray photoelectron spectroscopy. Am Mineral. 2005;90:1563-70.

9. Mahon D, Centeno S, Wypyski M, Salomon X, Bayer A. Technical study of three allegorical paintings by Paolo Veronese: The Choice between Virtue and Vice, Wisdom and Strength, and Mars and Venus United by Love. Metrop Mus Stud Art Sci Technol. 2010;1:83-108.

10. Pottasch $C$, Mensch K. Arsenic and apricots: understanding the sober still lifes of Adriaenn Coorte. In: Meeks N, Cartwright C, Meek A, Mongiatti A, editors. Historical technology, materials and conservation: SEM and microanalysis. London: Archetype Publications; 2012. p. 100-6.

11. Keune K, Mass J, Meirer F, Pottasch C, van Loon A, Hull A, et al. Tracking the transformation and transport of arsenic sulfide pigments in paints: synchrotron-based X-ray micro-analyses. J Anal Atomic Spectrom 2015:30(3):813-27. https://doi.org/10.1039/c4ja00424h.

12. Grube E. Three miniatures from Fustat in The Metropolitan Museum of Art in New York. Ars Orientalis. 1963:5:89-95.

13. Ettinghausen R. Islamic art and architecture, 650-1250. New Haven: Yale University Press; 2001.

14. The Metropolitan Museum of Art. https://www.metmuseumorg/art/colle ction/search/451193. Accessed 17 June 2018.

15. Suleman F. The lion, the hare and lustreware. In: Porter $V$, Rosser-Owen $M$, editors. Metalwork and material culture in the Islamic world. London: I.B. Tauris \& Co.; 2012. p. 379-91

16. Bloom J. The introduction of paper to the Islamic lands and the development of the illustrated manuscript. In: Roxburgh D, editor. Muqarnas: an annual on the visual culture of the Islamic world. Leiden: Brill; 2000. p. 17-23.

17. Lowin S. Encyclopedia of Jews in the Islamic world. Leiden: Brill; 2007.

18. Hoffman E. The beginnings of the illustrated arabic book: an intersection between art and scholarship. In: Roxburgh D, editor. Muqarnas: an annual on the visual culture of the Islamic world. Leiden: Brill; 2000. p. 37-52.

19. Carboni S. Trésors fatimides du Caire. In: Barrucand M, Antoine E, editors Paris: Institut du monde arabe; 1998. p. 99.
20. Burgio L, Clark RJH. Library of FT-Raman spectra of pigments, minerals, pigment media and varnishes, and supplement to existing library of Raman spectra of pigments with visible excitation. Spectrochim Acta Part A Mol Biomol Spectrosc. 2001;57:1491-521.

21. Nyquist RA, Putzing CA, Leugers MA. Infrared and Raman spectral atlas of inorganic compounds and organic salts. San Diego: Academic Press; 1997.

22. Image of hörnesite specimen from Ayers, Val d'Anniviers, Wallis, Switzerland. http://rruff.info/repository/sample/by minerals/Hornesite_R0703 36__Sample_Photo_16036__M.jpg. Accessed 31 May 2018.

23. Bentz J, Peterson R. Realgar and hörnesite precipitation in an ironpoor, sulfate-rich Mudflat, Laguna Chiar Khota, Bolivia. Can Mineral. 2017;55:1009-25.

24. Frost RL, Weier ML, Martens W, Theo Kloprogge J, Ding Z. Thermal decomposition of the vivianite arsenates -implications for soil remediation. Thermochim Acta. 2003:403(2):237-49.

25. Voigt D, Brantley S, Hennet R. Chemical fixation of arsenic in contaminated soils. Appl Geochem. 1996:11:633-43.

26. Onac B, Hess J, White W. The relationship between the mineral composition of speleothems and mineralization of breccia pipes: evidence from Corkscrew Cave, Arizona, USA. Can Mineral. 2007;45:1177-88.

27. Hornesite-magnesium arsenate-White Caps Mine, Manhattan, Nevada. Worthpoint Database.

28. Nevell TP, Zeronian SH. Cellulose chemistry and its applications. Chichester: Ellis Horwood; 1985

29. Liers J, Schwerdt P. The Battelle mass deacidification process equipment and technology. Restaurator. 1995:16:1-9.

30. Shahani CJ, Harrison G. Spontaneous formation of acids in the natural aging of paper. In: Daniels V, Donnithorne A, Smith P, editors. Works of art on paper books, documents, and photographs techniques and conservation. London: The International Institute for Conservation; 2002. p. 189-92.

31. Clapp AF. Curatorial care of works of art on paper. New York: Nick Lyons Books; 1987.

32. Bégin P, Deschâtelets S, Grattan D, Gurnagul N, Iraci J, Kaminska E, et al. The effect of air pollutants on paper stability. Restaurator. 1999;20:22-9.

33. Hey M. The washing and deacidification of paper. The paper conservator. J Inst Pap Conserv. 1979:4:66-80.

34. Carr D, Niven B, Campbell L. Effects of selected aqueous treatments on the properties of two papers. Stud Conserv. 2006:51(3):189-98.

35. van der Reyden D. Recent scientific research in paper conservation. J Am Inst Conserv. 1992:31:117-38.

36. Zervos $\mathrm{S}$, Alexopoulou I. Paper conservation methods: a literature review. Cellulose. 2015;22(5):2859-97.

37. Arney JS, Jacobs AJ, Newman R. The influence of deacidification on the deterioration of paper. J Am Inst Conserv. 1979;19:34-41.

38. Smith RD. Non-aqueous Deacidification: its philosophies, origin, development and status. Pap Conserv. 1988;12(1):31-4.

39. Kolar J, Novak G. Effect of various deacidification solutions on the stability of cellulose pulps. Restaurator. 1996;17:25-31.

\section{Submit your manuscript to a SpringerOpen ${ }^{\circ}$ journal and benefit from:}

- Convenient online submission

Rigorous peer review

- Open access: articles freely available online

- High visibility within the field

Retaining the copyright to your article

Submit your next manuscript at springeropen.com 